\title{
The influence of the gut microflora on the digestion of dietary and endogenous proteins: studies of the amino acid composition of the excreta of germ-free and conventional chicks
}

\author{
By D. N. SALTER AND ROSEMARY J. FULFORD \\ National Institute for Research in Dairying, Shinfield, Reading $R G 2{ }_{9} A T$
}

\begin{abstract}
I. To assess the part played by the microflora in the digestion of proteins, the amino acid composition of the excreta and the apparent and true digestibilities of individual amino acids were measured in germ-free (GF) and conventional (CV) chicks.
\end{abstract}

2. Three diets were used: diet $\mathrm{I}$, nitrogen-free; diet $2,280 \mathrm{~g}$ protein $/ \mathrm{kg}$ as $(\mathrm{g} / \mathrm{kg}):$ casein 80 , gelatin 100 and freeze-dried egg albumen 100 and diet $3,280 \mathrm{~g}$ protein $/ \mathrm{kg}$ as diet 2 but with heat-damaged instead of freeze-dried egg albumen. Half of the GF and half of the CV chicks received the $\mathrm{N}$-free diet in the first $7 \mathrm{~d}$ of test and the other half of each group received either diet 2 or diet 3 . In the second $7 \mathrm{~d}$ test period those chicks which had been given the $\mathrm{N}$ free diet received either diet 2 or diet 3 while those which had been given protein diets received the $\mathrm{N}$-free diet. Total amino acids were measured in hydrolysates of the soluble and insoluble fractions of the excreta collected in the last $3 \mathrm{~d}$ of each test period.

3. The amino acid composition of the soluble fraction of the excreta of chicks given either diet 2 or diet 3 differed markedly from that of chicks given the $\mathrm{N}$-free diet. The amino acid composition of the insoluble fraction of the excreta of chicks given diet 2 was similar to that of chicks given the $\mathrm{N}$-free diet, whereas that of chicks given diet 3 was markedly different and resembled egg albumen in composition.

4. In the soluble fraction of excreta from $\mathrm{CV}$ chicks given diets $\mathrm{I}$ and 2 the proportions of threonine, serine and glucosamine were lower and those of methionine, leucine, isoleucine and phenylalanine were higher than in those from GF chicks, particularly on diet I. In the insoluble fraction of excreta from CV chicks given these two diets, compared with GF chicks, there were lower proportions of serine and proline and higher proportions of cysteic acid and lysine, the latter particularly with diet $I$.

5. Lower proportions of threonine, serine and glucosamine were also observed in the soluble fractions of excreta from the CV chicks given diets I and 3 , compared with GF chicks, whereas the proportion of glutamic acid was higher. With these two diets the insoluble fraction from CV chicks contained a higher proportion of alanine. In each instance the environmental effect was greater with diet $\mathrm{I}$.

6. No effect of environment on either apparent or true digestibility of individual dietary protein amino acids was demonstrated, with the exception of threonine in diet 2 , the true digestibility of which was higher in GF than in CV chicks.

7. It was concluded that the gut microflora of the chick had little influence on the digestion of the proteins in the diets tested, but may serve an important role in the degradation of endogenous proteins and the recycling of $\mathrm{N}$.

In studies on the digestion of ${ }^{14} \mathrm{C}$-labelled proteins in chicks it was shown that separation of nitrogen from the ${ }^{14} \mathrm{C}$ moiety occurred under the influence of the gut microflora, and that the separated $\mathrm{N}$ was probably absorbed as ammonia (Salter \& Coates, I97I; Salter, 1973). The implication was that protein residues that escaped digestion in the upper gut were further digested in the lower gut by microbial proteases and that some deamination of liberated amino acids took place. Consequently differences should be found between germ-free (GF) and conventional (CV) chicks in the amino acid composition of the residues in the lower gut contents and excreta. In the experiment reported here, the effect of the microflora on the amino acid composition of the 
residues from good- and poor-quality dietary proteins and endogenous proteins has been studied by analysis of the amino acids in the excreta of groups of GF and CV chicks given protein diets containing unheated or heat-damaged egg albumen or a $\mathrm{N}$-free diet. The significance of the observed effects was assessed in terms of the effect of the microflora on the true and apparent digestibilities of the individual amino acids.

\section{MATERIALS AND METHODS}

\section{Chicks}

Chicks of the Rhode Island Red $\times$ Light Sussex cross were used. GF chicks were reared in Gustafsson isolators and CV chicks in a controlled-environment room (Salter \& Coates, r97I).

\section{Diets}

Three diets were used: diet I, N-free; diet 2, $280 \mathrm{~g}$ protein $/ \mathrm{kg}$ provided by $(\mathrm{g} / \mathrm{kg}$ diet): egg albumen I00, casein 80 and gelatin I00; and diet $3,280 \mathrm{~g}$ protein $/ \mathrm{kg}$ provided by ( $\mathrm{g} / \mathrm{kg}$ diet): heat-damaged egg albumen I00, casein 80 and gelatin 100 . The preparation of the unheated and heat-damaged egg albumen has been described by Salter \& Coates (I97I) and the composition of the diets by Salter, Coates \& Hewitt (1974).

\section{Design of experiments}

In a preliminary experiment to measure the proportions of protein, peptide and free amino acids in the lower gut contents, six GF and six CV chicks were reared from I to $\mathrm{I}_{4} \mathrm{~d}$ old on diet 2 , then transferred to diet 3 . At $\mathbf{2 4} \mathrm{d}$ they were fasted overnight and given a test meal of ro $g$ diet 3 introduced directly into the crop. The combined contents of the caecums and colons were collected from the anaesthetized chicks by washing out with warm saline, and then separated into saline-soluble and salineinsoluble fractions. The procedure has been described by Salter $\&$ Coates (I97I).

For the main experiment, chicks were housed in pairs in metabolism cages, and the two members of each pair were fed alike. Eight pairs of GF chicks and eight pairs of $\mathrm{CV}$ chicks were reared on diet 2. At $14 \mathrm{~d}$ of age the chicks were divided into two groups, each of four pairs of GF and four pairs of CV chicks. In one group, half of the chicks (two pairs GF and two pairs CV) received diet 2 and half received the $\mathrm{N}$-free diet (diet $\mathrm{r}$ ) for the next $7 \mathrm{~d}$ and the combined excreta of each pair of chicks was collected for the last $3 \mathrm{~d}$. For the next $7 \mathrm{~d}$ the diets were interchanged and excreta were again collected for the last $3 \mathrm{~d}$. In the second group the procedure was the same except that diet 2 was replaced by diet 3 . Amino acid analysis was carried out on the excreta from each pair of chicks, as excreta was not collected for individuals.

\section{Collection of excreta}

The combined droppings from each pair of chicks were collected into $200 \mathrm{ml}$ $0.05 \mathrm{M}-$ sulphuric acid (to prevent further microbial action and avoid loss of ammonia) in deep stainless-steel trays. They were removed daily, transferred to screw-capped polyethylene bottles, and frozen at $-20^{\circ}$. The three daily collections for each pair of 
chicks were pooled and homogenized. The suspension was then centrifuged for $15 \mathrm{~min}$ at $5^{\circ}$ and $9000 \mathrm{~g}$ in an MSE High-Speed I8 centrifuge (Measuring \& Scientific Equip ment Ltd, London SW $\mathrm{r}$ ). The clear soluble fraction was decanted and stored frozen at $-20^{\circ}$ and the sediment was freeze-dried.

\section{Analytical methods}

Amino acids and hexosamines. For total amino acids, samples of the excreta fractions soluble or insoluble in $0.05 \mathrm{M}$-sulphuric acid containing $5^{\circ} \mu \mathrm{g} \mathrm{N}$ were hydrolysed by refluxing with $6 \mathrm{M}-\mathrm{HCl}$ for $24 \mathrm{~h}$ in an oil-bath at $115^{\circ}$, then filtered, concentrated by rotary evaporation at $100^{\circ}$ and redissolved in 0. I I M-sodium citrate buffer at $\mathrm{pH} 2 \cdot 2$. The amino acid and hexosamine contents of the hydrolysates were determined with a JEOL Amino Acid Analyser (Model JCL-5AH, Japan Electron Optics Laboratory Co. Ltd, Tokyo, Japan). Under these conditions nearly $50 \%$ destruction of glucosamine occurs and there may be a greater loss of galactosamine (Nolan \& Smith, 1962). It was assumed that the contribution of urinary amino acids to the pattern of total amino acids excreted was negligible, since it has been reported (O'Dell, Woods, Laerdal, Jeffay \& Savage, 1960 ) that urinary amino acids comprise about $2 \%$ of urinary N. On this basis only I \% of the total excreted amino acids were of urinary origin when the unheated egg albumen diet was given and $0.6 \%$ when heat-damaged egg albumen was given.

For free amino acids in the contents of the caecums and colons, $4 \mathrm{ml}$ of each pooled saline-soluble fraction were treated with $6 \mathrm{ml}$ sulphosalicylic acid solution $(36 \mathrm{~g} / \mathrm{l})$ to precipitate proteins. After standing for $16 \mathrm{~h}$ at $4^{\circ}$, the suspensions were centrifuged at $9000 \mathrm{~g}$ for $20 \mathrm{~min}$ at $4^{\circ}$ and samples of the clear supernatant fraction were analysed for their amino acid content using an EEL Amino Acid Analyser (Evans Electroselenium Ltd, Halstead, Essex).

Other analytical methods. Total $\mathrm{N}$ was determined by a Kjeldahl micro-digestion procedure followed by estimation using a Technicon AutoAnalyzer (Technicon Instruments Co. Ltd, Basingstoke, Hants) of the ammonium sulphate formed (Ferrari, 1960). Uric acid was measured as described by Salter $e$ t al. (1974). A estimate of the 'peptide- $\mathrm{N}$ ' content of saline-soluble fractions of digesta was obtained from the difference between total non-uric acid- $\mathrm{N}$ and the sum of the measured free amino acid-N and precipitated protein- $\mathrm{N}$ in sulphosalicylic acid-treated samples.

Calculations of amino acid- $N$ digestibilities. The digestibility of $\mathrm{N}$ in a diet is defined as that proportion of the $\mathrm{N}$ consumed that is absorbed from the gut. In the calculation of true digestibility (TD) a correction is made for endogenous faecal $\mathrm{N}$, i.e. $\mathrm{N}$ voided during the period on a $\mathrm{N}$-free diet after a suitable period of adaptation:

$$
\left.\mathrm{TD}=\frac{\mathrm{N}_{\text {intake }}-\left(\mathrm{N}_{\mathrm{F}}-\mathrm{N}_{\mathrm{F}}\right. \text {, endogenous }}{}\right) .
$$

In the calculation of apparent digestibility (AD), no account is taken of endogenous faecal N:

$$
\mathrm{AD}=\frac{\mathrm{N}_{\text {intake }}-\mathrm{N}_{\mathrm{F}}}{\mathrm{N}_{\text {intake }}},
$$


where $\mathrm{N}_{\mathrm{F}}$ is faecal $\mathrm{N}$. For the calculations of individual amino acid digestibilities the appropriate values for dietary and faecal amino acid- $\mathrm{N}$ were substituted in the above formulas.

\section{Statistical analysis}

In the analyses of variance for amino acid composition, effects or interactions associated with periods (week $3 v$. week 4 ) were not significant, therefore standard errors of diet effects or interactions between environments and diets were derived from the interaction between diets and pairs of chicks within environments.

\section{RESULTS}

Distribution of $N$ in the contents of the lower gut of $G F$ and $C V$ chicks

In the preliminary experiment the pooled contents of the caecums and colons of six GF and six CV chicks were analysed for $\mathrm{N}$-containing compounds $5 \mathrm{~h}$ after they had received a Io $g$ dose of diet 3 . It was found that in GF chicks a higher proportion of the total $\mathrm{N}$ was soluble in saline than in $\mathrm{CV}$ chicks ( 0.86 and 0.63 respectively). This soluble $\mathrm{N}$ from the GF chicks contained a higher proportion of protein $(0 \cdot 16)$ and less free amino acid-N (O. $\left.{ }_{15}\right)$ than that from the CV chicks, for which the corresponding proportions of protein and free amino acid-N were 0.03 and 0.27 respectively. The proportions of peptide- $\mathrm{N}$ were about the same in the two environments ( 0.69 and 0.70 in GF and $\mathrm{CV}$ chicks respectively).

\section{The amino acid and hexosamine composition of the excreta of $G F$ and $C V$ chicks}

Diets I and 2. (a) Soluble fraction. Table I shows the total amino acid compositions and hexosamine contents of the $0.05 \mathrm{M}^{-} \mathrm{H}_{2} \mathrm{SO}_{4}$-soluble fraction of the excreta from pairs of $\mathrm{GF}$ and $\mathrm{CV}$ chicks that had been given the $\mathrm{N}$-free diet (diet $\mathrm{x}$ ) or the diet containing unheated egg albumen, casein and gelatin (diet 2). In chicks given diet 2 compared with chicks given diet $\mathbf{I}$, there were significantly higher proportions of aspartic acid, proline, glycine, alanine and arginine and lower proportions of threonine, glutamic acid, valine, leucine, tyrosine, phenylalanine, histidine and ammonia. There were also significantly lower proportions of laevulinic acid and galactosamine in chicks given diet 2. Significant effects of environment, particularly on diet I, were found with serine and glucosamine which were lower in the CV chicks than in GF chicks, and with leucine and phenylalanine which were slightly higher in CV chicks. An effect of environment averaged over the two diets was also apparent for methionine, which was higher in $\mathrm{CV}$ than in GF chicks. Although there were no average environmental effects for threonine and isoleucine the observed decrease in threonine and the increase in isoleucine were significant $(P<0.05)$ for $\mathrm{CV}$ chicks given diet $\mathrm{x}$.

(b) Insoluble fraction. The total amino acid compositions and hexosamine contents of the insoluble fraction of excreta from the groups of GF and CV chicks that had been given diets I or 2 are shown in Table 2. In the excreta of chicks given diet 2 , there were significantly lower proportions of threonine, valine, leucine, tyrosine and 
Vol. 32

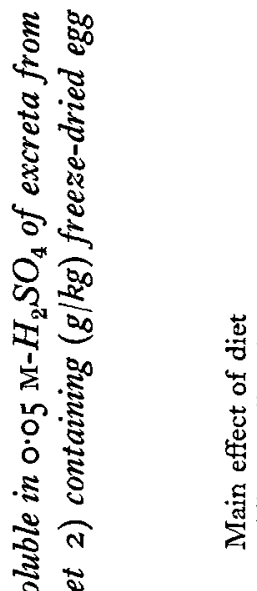

莺

岂

萑苋

恶总

2 i

兽

$\sum_{0}^{\infty} \cdot 5$

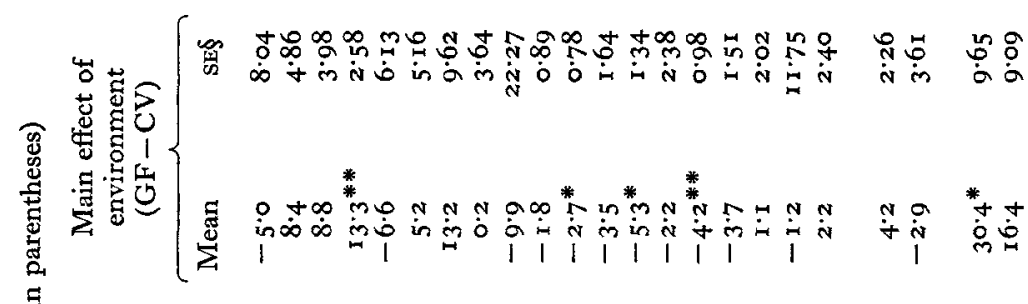

今

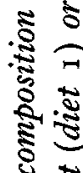

鄫 $\left\{\begin{array}{l}3 \\ 0 \\ 0 \\ 0\end{array}\right.$

( m

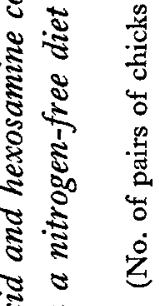

¿

$\cdot \frac{2}{20}$

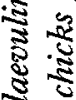

28

U

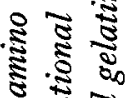

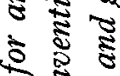

उ

\& 8

$\frac{5}{2} \sqrt{2} \cdot \frac{8}{2}$

䓀

$\stackrel{5}{8}$

恶

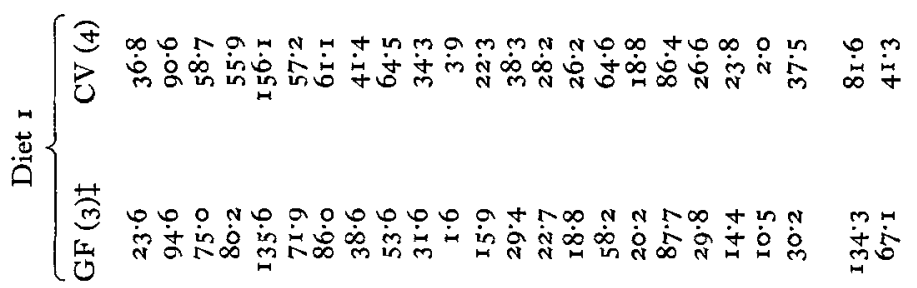

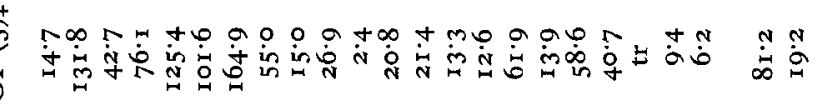




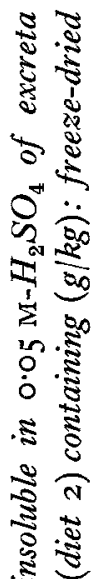

. ฐ) :

焉

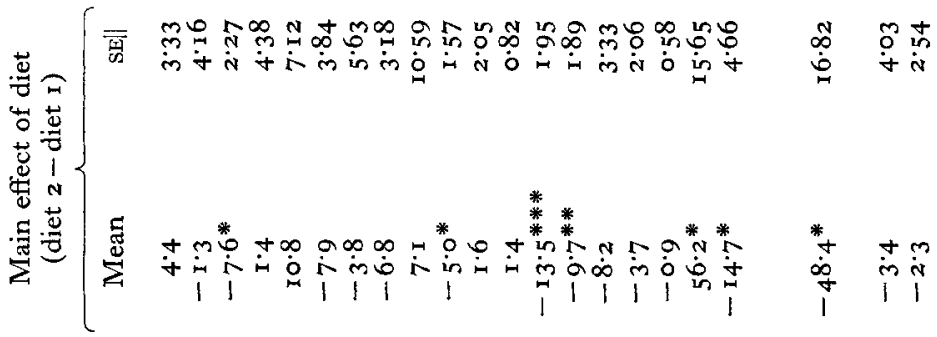

ชี.

$+\frac{2}{2}$

\&

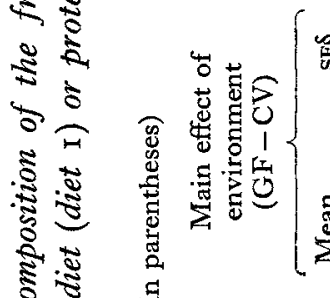

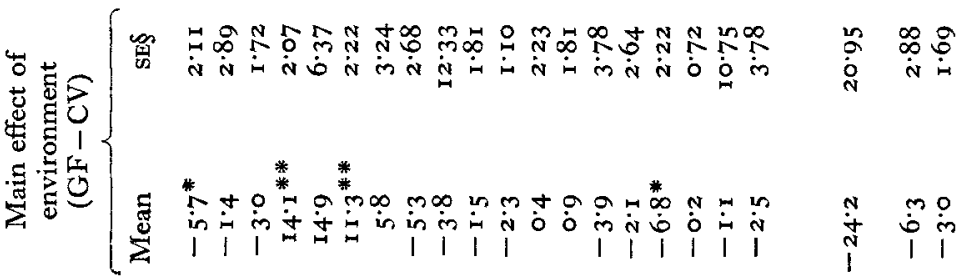

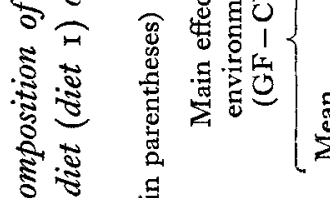

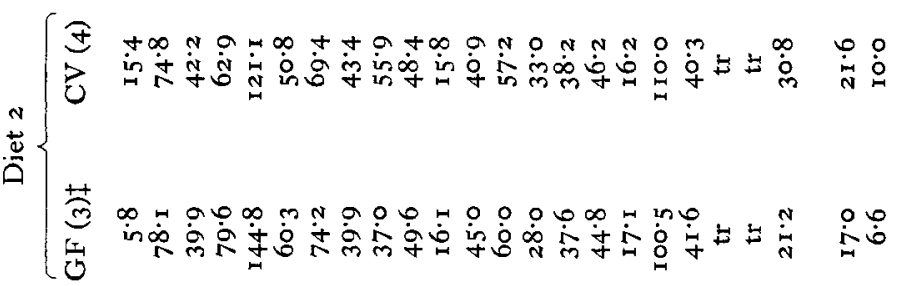

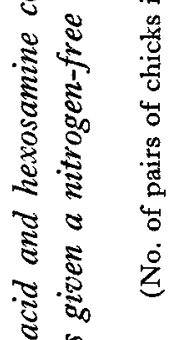

竎

蛋

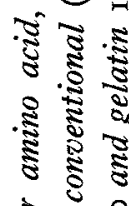

डे

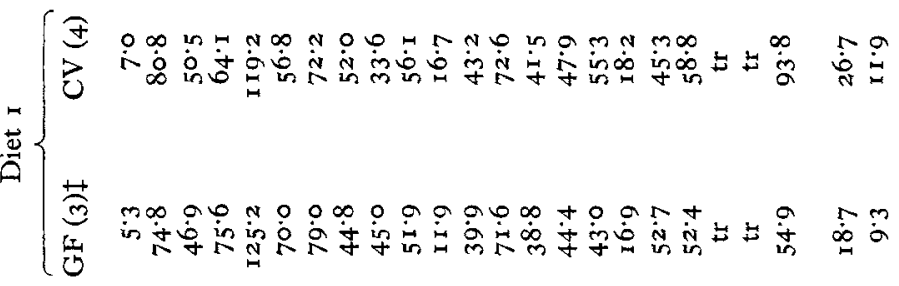

密

है :

स

i

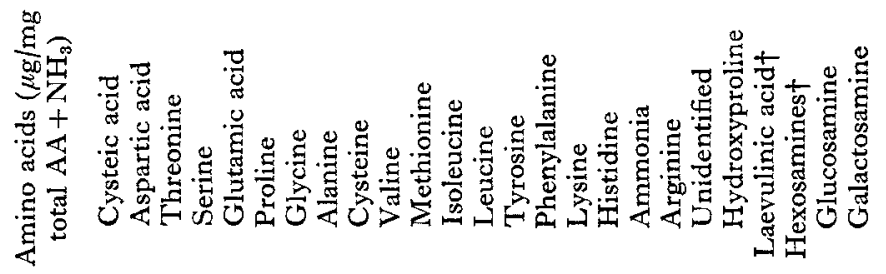


Vol. 32

0
0
0
0
0
0
0
0
0

覆

宊

空

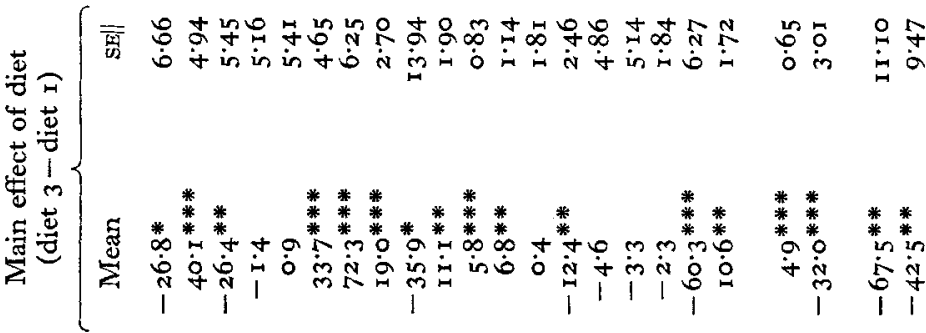

in

O

.

$\stackrel{0}{0}$

क

공

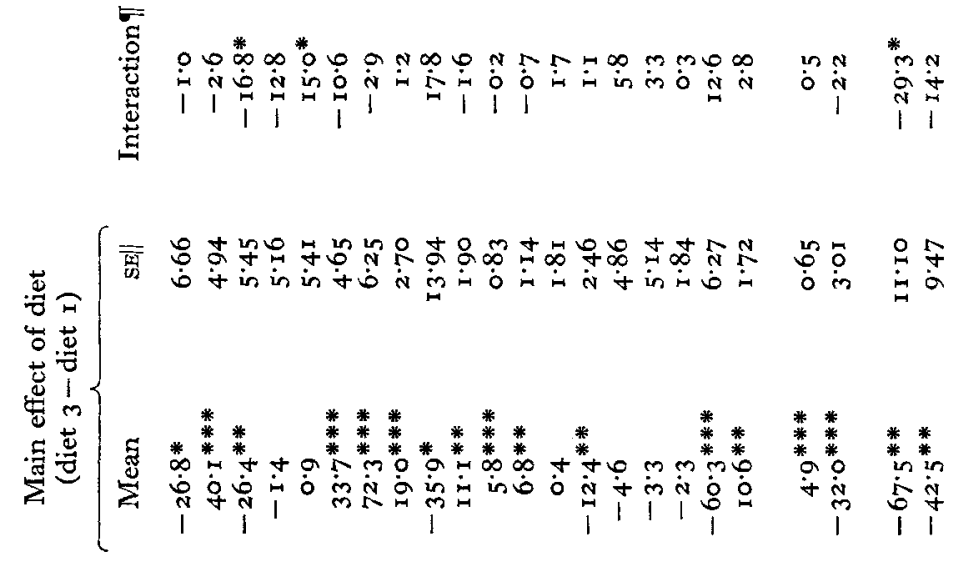

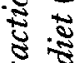

$+\frac{1}{2}$

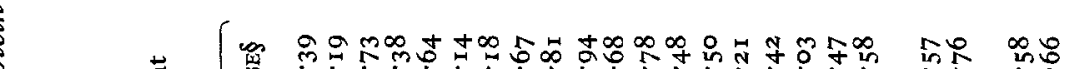

b $\quad$ 范

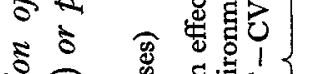

.

焉

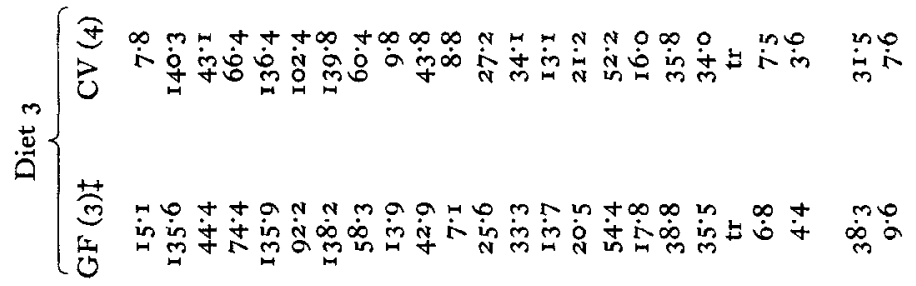

$\cdot \frac{3}{2}$

$\frac{\sqrt{3}}{\sqrt[3]{3}} \cdot \frac{2}{2}$

合 8

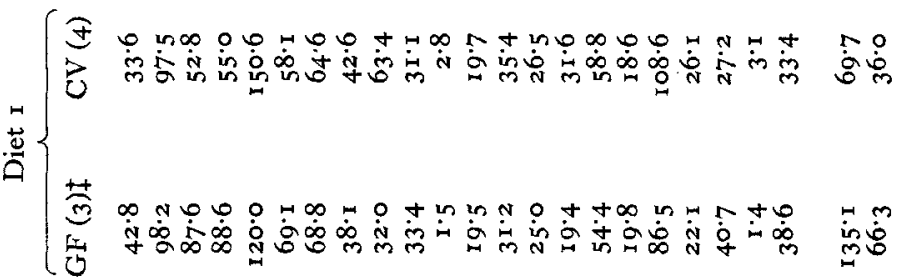

究

․ $\frac{8}{2}$

胥

용

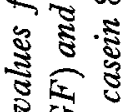

ङ 8

$\sum \frac{1}{2}$

$\therefore$

$\stackrel{0}{2} \approx$

ज

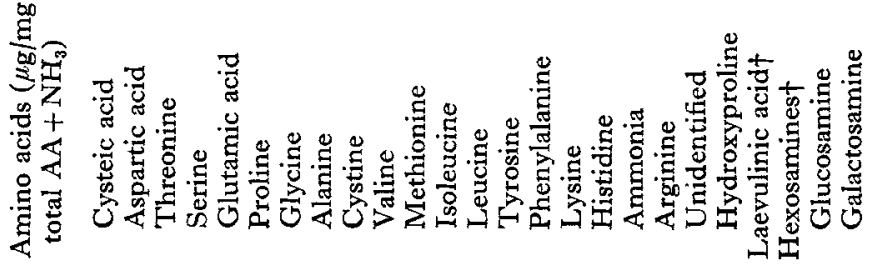

*. 


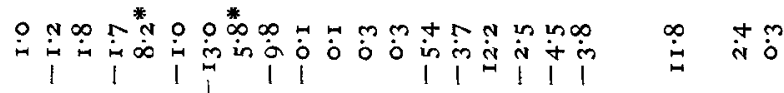

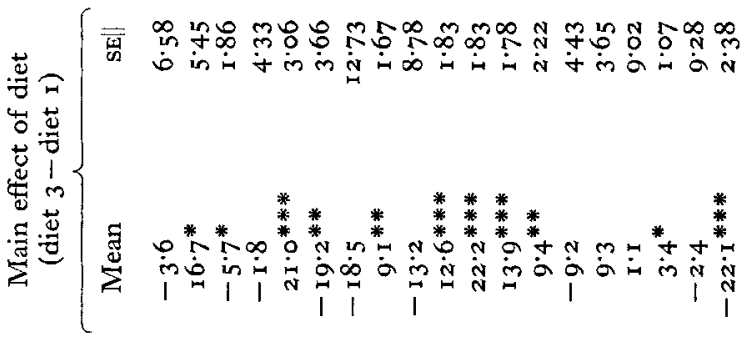

$\frac{2}{3}$

un so

o.

.5

$\stackrel{2}{\Xi}$

$\frac{\text { क }}{8}$

:

: $2 \cdot \frac{1}{2}$

के

iा एक

के

$\frac{\cos ^{2}}{2}$

है

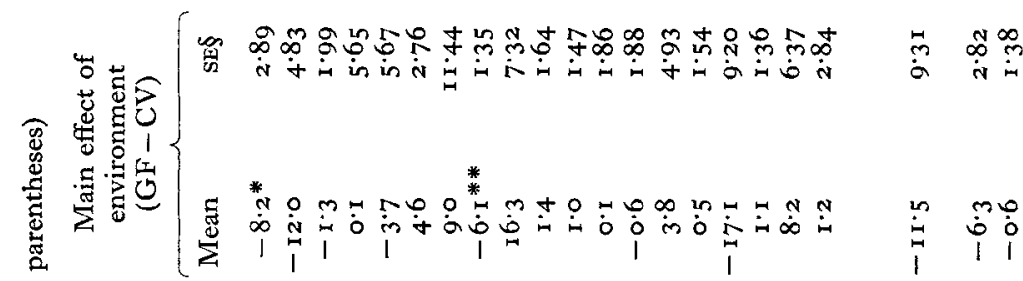

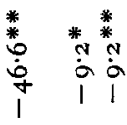

8 $:$ :

.

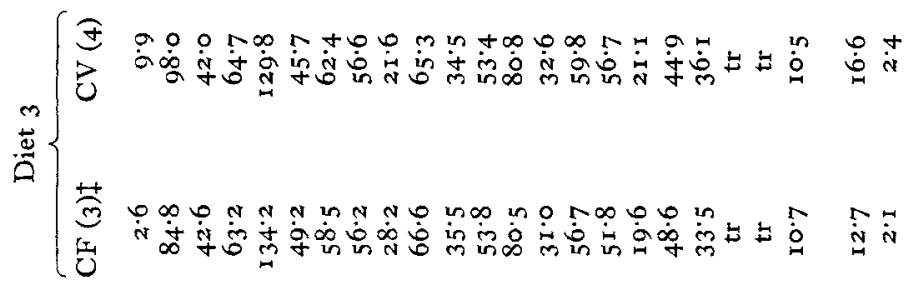

:

零。

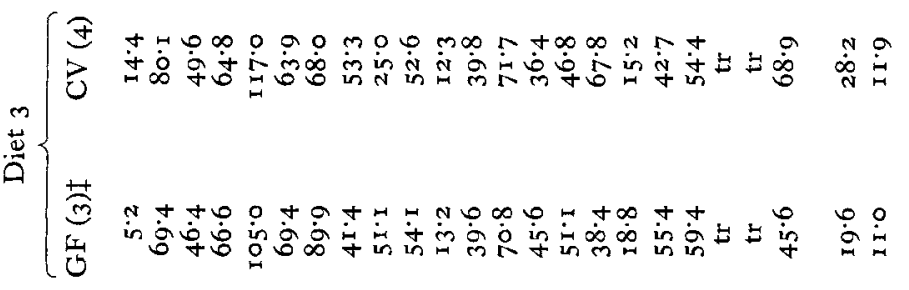

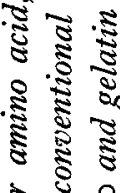

है $\infty$

胥

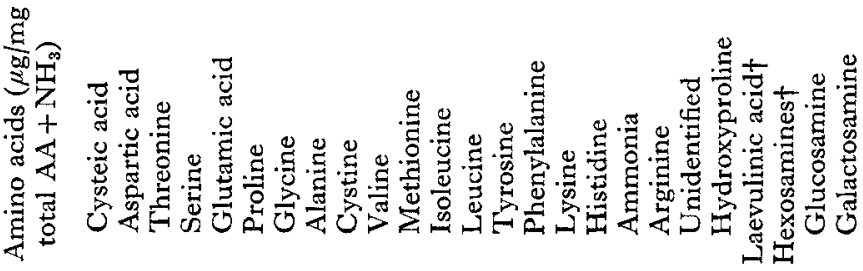

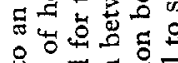

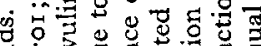


arginine, and a higher proportion of ammonia than in the excreta of chicks given diet $\mathrm{I}$. The proportion of laevulinic acid was also markedly lower in the excreta of chicks given diet 2. Compared with the GF environment, significantly lower proportions of serine and proline and higher proportions of cysteic acid and lysine were found in the CV environment. The increase in lysine was more marked in chicks given diet I $(P<0.01)$ than in those given diet 2 , for which it was not significant. Although there were relatively large increases in the mean proportions of laevulinic acid and hexosamines and a smaller increase in the proportion of alanine excreted in the CVcompared with the GF-environment, the results were variable and the differences were not significant $(P>0.05)$.

Diets $\mathrm{I}$ and 3. (a) Soluble fraction. In Table 3 the total amino acid compositions and hexosamine contents of the excreta of the groups of GF and CV chicks that had been given diets $\mathrm{I}$ or 3 are presented. A marked and significant mean effect of diet was apparent, proportions of aspartic acid, proline, glycine, alanine, valine, methionine, isoleucine, arginine and hydroxyproline being higher, and proportions of cysteic acid, threonine, cystine, tyrosine and ammonia lower in chicks given diet 3 than in those given diet $\mathbf{I}$. The proportions of laevulinic acid, glucosamine and galactosamine were also markedly lower for chicks given diet 3. A mean effect of environment on the proportions of threonine, serine and glucosamine, which were lower in CV chicks than in GF chicks, and on the proportion of glutamic acid, which was higher in the CV chicks, was observed. These effects were almost entirely due to large and significant differences between GF and CV chicks given diet I $(P<0.0$ I for threonine, serine and glucosamine; $P<0.05$ for glutamic acid).

(b) Insoluble fraction. The effects of diet and environment on the amino acid compositions and hexosamine contents of the insoluble fraction of the excreta of chicks given diet I or diet 3 are shown in Table 4 . There was a pronounced diet effect, there being significantly higher proportions of aspartic acid, glutamic acid, alanine, valine, methionine, isoleucine, leucine, and histidine, and lower proportions of threonine, proline, arginine, laevulinic acid and hexosamines in chicks given diet 3 than in those given diet $\mathrm{I}$. A significant difference between environments with diet I was established for alanine only, which was higher in CV than in GF chicks.

\section{True and apparent digestibility of individual amino acids}

The results for true and apparent digestibility showed, as expected, that there were significant differences between diets 2 and 3 , the mean digestibility of each amino acid being greater in diet 2 than that for diet 3 . The average value of the true digestibility of sixteen amino acids in diet 2 was 0.908 in GF chicks and 0.893 in CV chicks, and in diet 3 it was 0.698 in GF chicks and 0.730 in CV chicks. The corresponding values for apparent digestibility in GF and CV chicks respectively were 0.868 and 0.863 (diet 2) and 0.703 and 0.696 (diet 3). No significant average environmental effects or interactions between environments and diets were established although for each amino acid the mean true digestibility was higher for GF chicks than for CV chicks for diet $\mathbf{2}$ and lower for diet $\mathbf{3}$. 
Table 5. Mean values for the amino acid composition ( $\mu$ g/mg total amino acids + ammonia) of egg albumen and of the fraction insoluble in $0.05 \mathrm{M}-\mathrm{H}_{2} \mathrm{SO}_{4}$ of excreta from groups of three pairs of germ-free chicks given diet $2 *$ or diet $3 \dagger$

\begin{tabular}{|c|c|c|c|c|c|}
\hline & $\begin{array}{c}\text { Egg } \\
\text { albumen } \\
(a)\end{array}$ & $\begin{array}{c}\text { Diet } 2 \\
(b)\end{array}$ & $b: a$ & $\begin{array}{c}\text { Diet } 3 \\
(c)\end{array}$ & $c: a$ \\
\hline Aspartic acid & $104: 5$ & $78 \cdot 1$ & 0.75 & $84 \cdot 8$ & $0.8 \mathrm{I}$ \\
\hline Threonine & $48 \cdot 3$ & $39^{\circ} 9$ & 0.83 & $42 \cdot 6$ & 0.88 \\
\hline Serine & $73 \cdot 5$ & $79 \cdot 6$ & 1.08 & $63 \cdot 2$ & 0.86 \\
\hline Glutamic acid & $141 \cdot 8$ & 144.8 & 1.02 & $134^{\prime 2}$ & 0.95 \\
\hline Proline & $3+6$ & $60 \cdot 3$ & I.9I & $49^{-2}$ & $x \cdot 56$ \\
\hline Glycine & $36 \cdot 6$ & $74 \cdot 2$ & 2.03 & $58 \cdot 5$ & $I \cdot 60$ \\
\hline Alanine & $58 \cdot 9$ & $39 \cdot 9$ & 0.68 & $56 \cdot 2$ & 0.95 \\
\hline Valine & $68 \cdot 5$ & $49 \cdot 6$ & 0.72 & 66.6 & 0.97 \\
\hline Methionine & 39.8 & $16 \cdot 1$ & 0.40 & 35.5 & 0.89 \\
\hline Isoleucine & 53.9 & $45^{\circ} \circ$ & 0.83 & $53 \cdot 8$ & 1.00 \\
\hline Leucine & 88.8 & $60 \cdot 0$ & 0.68 & $80 \cdot 5$ & 0.91 \\
\hline Tyrosine & $39 \cdot 7$ & $28 \cdot 0$ & 0.71 & $31 \cdot 0$ & 0.78 \\
\hline Phenylalanine & $62 \cdot 1$ & $37 \cdot 6$ & $0.6 \mathrm{r}$ & $56 \cdot 7$ & $0.9 \mathrm{I}$ \\
\hline Lysine & $6 r \cdot 4$ & $44 \cdot 8$ & 0.73 & $5 \mathrm{I} \cdot 8$ & 0.84 \\
\hline Histidine & $24 \cdot 1$ & $17 \cdot 1$ & 0.71 & 19.6 & $0.8 \mathrm{I}$ \\
\hline Arginine & $5 \mathrm{I} \cdot 8$ & $4 I \cdot 6$ & 0.80 & $33 \cdot 5$ & 0.65 \\
\hline Mean ratio & - & - & 0.91 & - & 0.96 \\
\hline Range of ratios & - & - & $0.40-2.03$ & - & $0.65-r \cdot 60$ \\
\hline
\end{tabular}

* Containing $(\mathrm{g} / \mathrm{kg})$ : freeze-dried egg albumen 100 , casein 80 and gelatin 100 .

$\uparrow$ Containing $(\mathrm{g} / \mathrm{kg})$ : heat-damaged egg albumen 100 , casein 80 and gelatin roo.

However, for both true and apparent digestibility it was evident that there was less variation within diet 2 than within diet 3 , although the numbers of observations were limited. In separate statistical analyses for each diet, a significant effect of environment $(P<0.05)$ was established with diet 2 for the true digestibility of threonine, the values being 0.888 and 0.862 for $\mathrm{GF}$ and $\mathrm{CV}$ chicks respectively. (SE of difference 0.0075 , with $4 \mathrm{df}$, based on the variation between pairs of chicks within environments for diet 2.)

\section{DISCUSSION}

The results of the preliminary experiment showed that in the saline-soluble contents of the lower digestive tract of GF chicks the proportion of protein was higher and that of free amino acids lower than in CV chicks. This suggested that the microflora played a part in the further breakdown of protein to amino acids, and encouraged further investigation.

In the main experiment the three dietary treatments were chosen to assess the influence of the microflora on the amino acid composition of the residues of endogenous $\mathrm{N}$ secretions (diet $\mathrm{I}$ ), of a good-quality, well-digested protein mixture (diet 2), and of a protein mixture containing a poorly digested protein (diet 3 ), and to measure the effect of the microflora on the digestibility of the individual amino acids supplied by diets 2 and 3 . It is clear from the results presented in Table $\mathrm{I}-4$ that the influence of dietary protein on the amino acid composition of the excreta of chicks was much greater than that of the microflora. 
Considering first the influence of diet on amino acid composition, it is apparent that, comparing diet 2 with diet $I$, the dietary protein had a much more marked effect on the soluble fraction of the excreta (Table $\mathrm{I}$ ) than on the insoluble fraction (Table 2). This indicates that the residues of the dietary protein in this instance were mainly in the soluble fraction, the insoluble fraction differing little in composition from that of the endogenous secretions. Comparing diet 3 with diet $\mathbf{I}$, however, in chicks given diet 3 both the soluble and insoluble fractions differed markedly from the corresponding fractions for chicks given diet I (Tables 3 and 4 ) showing that residues of dietary protein were present in sufficiently high proportion in both fractions to mask the amino acid pattern due to endogenous material. Furthermore, a subjective comparison of the amino acid composition of the insoluble fraction of the excreta of GF chicks given heat-damaged (but not freeze-dried) egg albumen as part of their dietary protein with that of egg albumen itself (Table 5) shows that they were closely similar. The divergence of individual amino acids in this fraction from the pattern for egg albumen (except for tyrosine and arginine) can be explained largely by the effect of the endogenous protein amino acids, represented by the results for the GF chicks on diet I (Table 4). Thus it is probable that a large proportion of the insoluble material remaining in the excreta of GF chicks given diet 3 was undigested heat-damaged egg albumen. In the GF chicks that had been given the $\mathrm{N}$-free diet, the faecal $\mathrm{N}$ would have consisted mainly of endogenous secretions (enzymes and mucoproteins) and mucosal cell debris. Mucoproteins characteristically contain high proportions of threonine, serine, proline, glucosamine and galactosamine (Bella \& Kim, 1972; Cetta, Pallavicini, Callatroni \& Castellani, 1972) and the enzymes trypsin, chymotrypsin and pepsin are also rich in threonine and serine. The relatively high proportions of threonine and the hexosamines in the soluble but not the insoluble protein of the excreta of GF chicks given diet I (Tables I and 3, cf. 2 and 4) suggest that the mucoproteins were present mainly in the soluble fraction. The proportion of laevulinic acid, which was also more abundant in excreta from chicks given the $\mathrm{N}$-free diet than in those from chicks given protein diets, was however apparently higher in the insoluble than in the soluble fraction (cf. Tables $I$ and 2 or 3 and 4), suggesting that it may have been largely derived from mucosal cell debris.

The influence of the microflora on the amino acid composition of the excreta was not large. The effect of the gut micro-organisms on the composition of the soluble fractions from chicks given diets I and 2 (Table I) indicates destruction of threonine, serine and glucosamine and synthesis of methionine, isoleucine, leucine and phenylalanine. As these are net effects, a decrease in the proportions of these particular amino acids does not necessarily indicate their selective destruction but rather the breakdown of proteins rich in these amino acids, the $\mathrm{N}$ of which may be taken up by gut micro-organisms or the host either in the form of amino acids or as ammonia after deamination. The effect of environment was much larger in the excreta of chicks given the $\mathrm{N}$-free diet than of those given diet 2, and suggests a preferential action of the microflora on mucoproteins. With the same two diets, the influence of the microflora on the insoluble fractions of the excreta, which in GF chicks was presumably composed mainly of mucosal cell debris, and which in the CV chicks contained microbial 
cells in addition, was shown by destruction of serine and proline and synthesis of lysine and possibly also of cysteic acid, although the latter was probably partly formed from cystine during acid-hydrolysis of the samples. Other workers (Combe \& Pion, 1966) found that the gut microflora similarly affected the amino acid composition of a fraction of rat caecum contents that was insoluble in ethanol and trichloroacetic acid; they reported increases in proportions of lysine and aspartic acid and decreased proportions of proline, glycine and serine.

The results obtained with diets $I$ and 3 (Tables 3 and 4 ) also showed destruction in the soluble fractions of hexosamines and amino acids characteristic of the mucoproteins in $\mathrm{CV}$ chicks, but the increase in methionine, isoleucine, leucine and phenylalanine were not significant. However, the increase in glutamic acid, particularly in chicks given the $\mathrm{N}$-free diet, which was also apparent in the comparison of diets $I$ and 2 (Table $I$ ), was significant. The influence of the microflora on the insoluble fraction (Table 4) was small. The significant increase in alanine in CV chicks was due almost entirely to an increase in this amino acid in birds given the $\mathrm{N}$-free diet and is in agreement with a similar but non-significant increase found in chicks given diets I and 2 (Table 2). The increase in cysteic acid with both diets also confirms that found with diets I and 2 . The cysteic acid values did not parallel those for cystine, suggesting that it was not all produced from cystine during acid-hydrolysis of the excreta. A considerable increase in the proportion of lysine in CV chicks was observed, as with diets $\mathrm{I}$ and 2 , but on this occasion the increase was significant only at $P<0 \cdot \mathrm{I}$ for diet $\mathrm{I}$.

It is evident therefore that the microflora demonstrated little ability to modify the composition of the undigested heat-damaged egg albumen, and that those bonds formed within the protein as a result of heating which were not hydrolysed by the host's proteolytic enzymes were not susceptible to microbial attack. This finding is in accord with the results of Erbersdobler \& Riedel (1972), who concluded that gut micro-organisms were unable to break down soya-bean protein that had been severely damaged by heating at $140^{\circ}$ for $24 \mathrm{~h}$. It is nevertheless clear that the microflora attacked proteins of endogenous origin and, assuming that the $\mathrm{N}$ released was absorbed by the chick it could have some importance in the conservation of endogenous $\mathrm{N}$. In this respect this function of the microflora would be analogous to its role in the recycling of endogenous $\mathrm{N}$ secreted into the gut as urea (Richards, 1972). These results are also consistent with our previous observations that GF chicks excrete more endogenous $\mathrm{N}$ than do CV chicks (Salter et al. 1974). It is unlikely that the observed microbial synthesis of the essential amino acids, lysine, methionine, isoleucine, leucine and phenylalanine would be of any value to the host in the absence of coprophagy.

That the microflora played little part in the digestion of dietary proteins was clear from the absence of a significant effect of environment on either the true or apparent digestibility of any amino acid except threonine. In the latter instance the small increase in true digestibility (but not in apparent digestibility) of threonine in diet 2 in GF compared with $\mathrm{CV}$ chicks was presumably due to the higher amounts of endogenous threonine in the GF chick excreta, since the contribution to faecal $\mathrm{N}$ of any amino acid that was destroyed by the microflora in CV chicks would have been underestimated. Similar small increases in the values calculated for true digestibility 
would be expected for other amino acids which were decreased due to the action of the microflora on endogenous proteins. The proportion of endogenous $N$ to total $N$ in the excreta of chicks given diets 2 and 3 appeared, however, to be small, as the amino acid patterns differed strikingly from that of the GF chicks given $\mathrm{N}$-free diet, and with the degree of biological variation found in these experiments the effect on true digestibility would be difficult to detect.

It may be concluded from these results that the microflora of the lower part of the alimentary tract has little influence on the digestion of dietary proteins in chicks. It may, however, serve an important role in the degradation of endogenous proteins and the recycling of $\mathrm{N}$. The action of the microflora on endogenous $\mathrm{N}$ may result in slight underestimation of the digestibility of amino acids in CV chicks.

The authors are indebted to Dr M. E. Coates and Dr J. W. G. Porter for helpful discussions and advice in planning the work and to Mrs K. E. A. Smith and Mr J. E. Cockburn for technical assistance.

\section{REFERENCES}

Bella, A. \& Kim, S. Y. (1972). Archs Biochem. Biophys. 150, 679.

Cetta, G., Pallavicini, G., Callatroni, A. \& Castellani, A. A. (1972). Ital. F. Biochem. $21,275$.

Combe, E. \& Pion, R. (I966). Annls Biol. anim. Biochim. Biophys. 6, 255.

Erbersdobler, H. \& Riedel, G. (1972). Arch. Geflügelk. 6, 2 I8.

Ferrari, A. (1960). Ann. N.Y. Acad. Sci. 87, 792.

Nolan, C. \& Smith, E. L. (1962). F. biol. Chem. 237, 446.

O'Dell, B. L., Woods, W. D., Laerdal, O. A., Jeffay, A. M. \& Savage, J. E. (r960). Poult. Sci. 39, 42. Richards, P. (1972). Am. F. clin. Nutr. 25, 6 I $_{5}$.

Salter, D. N. (1973). Proc. Nutr. Soc. 32, 65.

Salter, D. N. \& Coates, M. E. (1971). Br. F. Nutr. 26, 55.

Salter, D. N., Coates, M. E. \& Hewitt, D. (1974). Br. $\mathscr{Y}$. Nutr. 3r, 307. 